\title{
Simulation of the behavior of aluminum alloys welded in Friction Stir Welding FSW (Case of AA5083 and AA 6082)
}

\author{
Bousekrine Taha Bounini, Benattou Bouchouicha \\ University of Sidi Bel Abbes, Algeria \\ Tahabounini@yahoo.fr,benattou_b@yahoo.fr
}

\author{
Abdelkader Ghazi \\ University of Mascara, Algeria \\ ghaziaek@yahoo.fr
}

\begin{abstract}
The friction stir welding FSW is a topical technique to date, either for experimental or numerical research topics. Based on the fact that the majority of the heat generated, comes from the contact between the workpiece and the shoulder, and from the work of friction done by the pin. Thus, it is crucial to approach the reality, by simulating the most of the conditions, related to the FSW process. The development of a numerical model allows us, not only to simulate the FSW welding process, but also to conduct a parametric study and vary the welding conditions as desired.

Therefore, a numerical study is conducted on the friction stir welding of AA 5083H111 work piece, in order to perceive the optimal settings. A three dimensional model designed by ANSYS APDL was used.

Before proceeding with this, a preliminary experimental study was carried out on FSW welded AA 6082 -T6 specimens and base material, using tensile and fatigue tests. The numerical results obtained, essentially longitudinal residual stresses, are compared to other studies, experimental and numerical.
\end{abstract}

KEYwORDS. FSW; Parametric Study; AA5083H111; AA 6082-T6; Fatigue test.

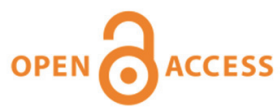

Citation: Bounini, T., Bouchouicha, B., Ghazi, A., Simulation of the behavior of Aluminium Alloys welded in FSW (Case of AA5083, AA6082), Frattura ed Integrità Strutturale, 46 (2018) 1-13.

Received: 28.03.2018

Accepted: 17.07 .2018

Published: 01.10.2018

Copyright: (C) 2018 This is an open access article under the terms of the CC-BY 4.0, which permits unrestricted use, distribution, and reproduction in any medium, provided the original author and source are credited.

\section{INTRODUCTION}

$\mathrm{F}$ riction stir welding (FSW) is a solid-state welding technique that involves the joining of metals without filler materials. A cylindrical rotating tool plunges into a rigidly clamped workpiece and moves along the joint to be welded. As the tool moves along the joint, heat is generated by friction between the tool shoulder and the workpiece. Additional heat is generated by plastic deformation of the workpiece material. The generated heat results in thermal softening of the workpiece material. The translation of the tool causes the softened workpiece material to flow from the 
front to the back of the tool where it consolidates. As cooling occurs, a solid continuous joint between the two plates is formed. No melting occurs during the process, and the resulting temperature remains below the solidus temperature of the metals being joined. FSW offers many advantages over conventional welding techniques, and has been successfully applied in the aerospace, automobile, and shipbuilding industries.

Thermal and mechanical behaviors are mutually dependent during the FSW process. Because the temperature field affects stress distribution, this example uses a fully thermo-mechanically coupled model. The model consists of a coupled-field solid element with structural and thermal degrees of freedom. The model has two rectangular steel plates and a cylindrical tool.

All necessary mechanical and thermal boundary conditions are applied on the model. The simulation occurs over three load steps, representing the plunge, dwell, and traverse phases of the process (Fig. 1) [1].

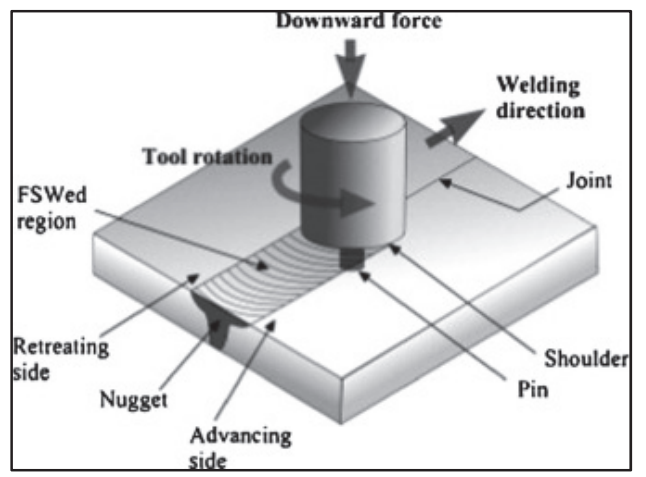

Figure 1: Schematic drawing of FSW process [2].

Numerical analysis of friction stir welding will allow many different welding processes to be simulated in order to understand the effects of changes in different system parameters before physical testing, which would be time-consuming or prohibitively expensive in practice [2].

This model assumes that two sheets of AA $5083 \mathrm{H} 111$ are welded by a rotating tool. This model takes into account the actual interaction between the tool and the workpiece, and the deformation of the material around the tool. It should be noted that most of the finite element FE models, consider the two sheets as one, or simulate the heat flux without simulating the tool, or a part of the tool.

The welding parameters, such as the variation of the welding speed, the rotation speed, and the material of the welded sheets, and their effects on the longitudinal stress, and on the distribution of the temperature flow.

An experimental study was carried out, for the purpose of defining the impact of the change of welding parameters on the tenacity of welded joints. The friction stir welding is done using a milling machine. Fatigue and tensile tests were carried out on test tubes of material Alluminium alloy 6082-T6.

\section{EXPERIMENTAL STUDY ON AA6082-T6}

$\mathrm{O}$ ur study focuses on the characterization of two materials 6082-T6 (Base material and FSW welded material). The characterization tests are based on two essential tests, tensile test to identify the behavioral laws of the different materials and fatigue test to see the evolution of a crack in the different configurations.

The chemical composition of the studied alloy is reported in the table below:

\begin{tabular}{cccccccccc}
\hline Al Alloy & $\mathrm{Si}$ & $\mathrm{Mg}$ & $\mathrm{Fe}$ & $\mathrm{Cu}$ & $\mathrm{Mn}$ & $\mathrm{Cr}$ & $\mathrm{Zn}$ & $\mathrm{Ti}$ & $\mathrm{Al}$ \\
6082-T6 & 1.3 & 1.2 & 0.5 & 0.1 & 1.0 & 0.25 & 0.2 & 0.1 & 98.3 \\
\hline
\end{tabular}

Table 1: The chemical composition of AA 6082-T6.

\section{Tensile Test}

For the different parts of the mechanical tests allowing the characterization of the materials, we carried out simple tensile tests on "dumbbell" specimens machined in aluminum sheets (longitudinal). The geometry of the specimens is described in Fig. 2. 
The following figure shows the true stress-true strain curves that characterize an elasto-plastic behavior of the studied materials.

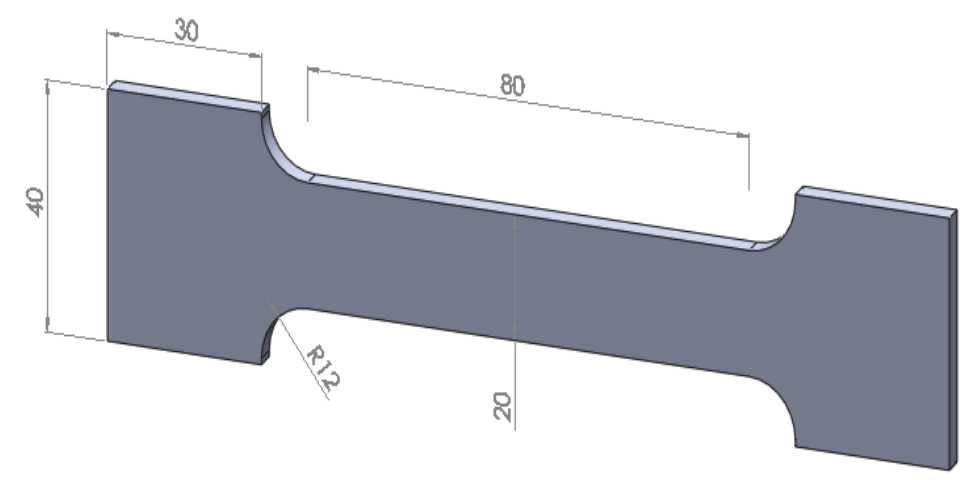

Figure 2: Details of the dumbbell specimen.

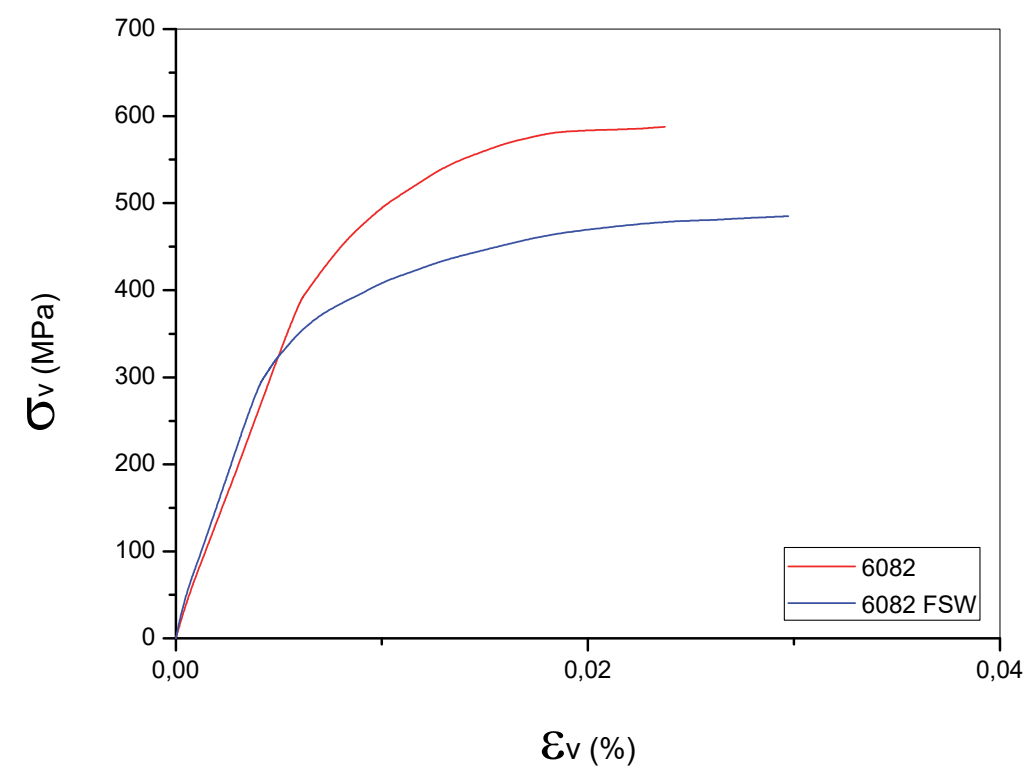

Figure 3: Tensile behavior of 6082 T6 aluminum alloy with and without welding.

The usual mechanical characteristics of the two materials are given in Tab. 2 below:

\begin{tabular}{cccccccc}
\hline Material & $\begin{array}{c}\mathrm{E} \\
(\mathrm{MPa})\end{array}$ & $\begin{array}{c}\sigma_{\mathrm{e}} \\
(\mathrm{MPa})\end{array}$ & $\begin{array}{c}\sigma_{\max } \\
(\mathrm{MPa})\end{array}$ & $\begin{array}{c}\varepsilon_{\mathrm{y}} \\
(\%)\end{array}$ & $\begin{array}{c}\varepsilon_{\text {failure }} \\
(\%)\end{array}$ & $\begin{array}{c}\mathrm{K} \\
(\mathrm{MPa})\end{array}$ & $\mathrm{n}$ \\
$\mathrm{Al}$ 6082-T6 & 74000 & 314 & 487 & 0.0046 & 0.029 & 1351 & 0.21 \\
$\mathrm{Al}$ 6082-T6 FSW & 69000 & 260 & 391 & 0.0038 & 0.019 & 848 & 0.19 \\
\hline
\end{tabular}

Table 2: Tensile Mechanical characteristics.

The conventional yield stress in the base material $(314 \mathrm{MPa})$ is well above the yield strength in FSW welded specimens (260MPa).

\section{Fatigue Test}

The cracking tests were carried out on CT50 test specimens of thickness $06 \mathrm{~mm}$, in accordance with ASTM-E-647 norm, the dimensions of which are given in Fig. 4.

The cracking tests were carried out at the University of Sidi Belabbes, on an INSTRON electrohydraulic machine of capacity $100 \mathrm{KN}$ in static and $50 \mathrm{KN}$ in dynamics. 
The crack length was measured using a magnifying optical binocular bezel and a stroboscope mounted on a device attached to the machine.

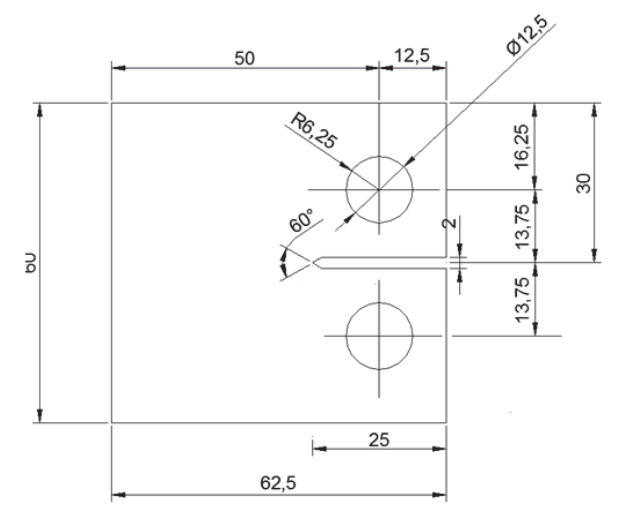

Figure 4: Dimensions of the CT50 specimen used for cracking tests.

\section{Propagation rates}

The fatigue crack propagation tests were carried out for both materials (Fig. 5), in the range of speeds between $4.10^{-5}$ and $2.10^{-2} \mathrm{~mm} /$ cycle at ambient air and with a load ratio $(\mathrm{R}=0.1)$.

The values of $\Delta \mathrm{K}$ vary from:

- 10 to 47 in aluminum 6082-T6

- 10 to 45 in FSW welded aluminum 6082-T6.

The results obtained for the different specimens are represented by Fig. 5:

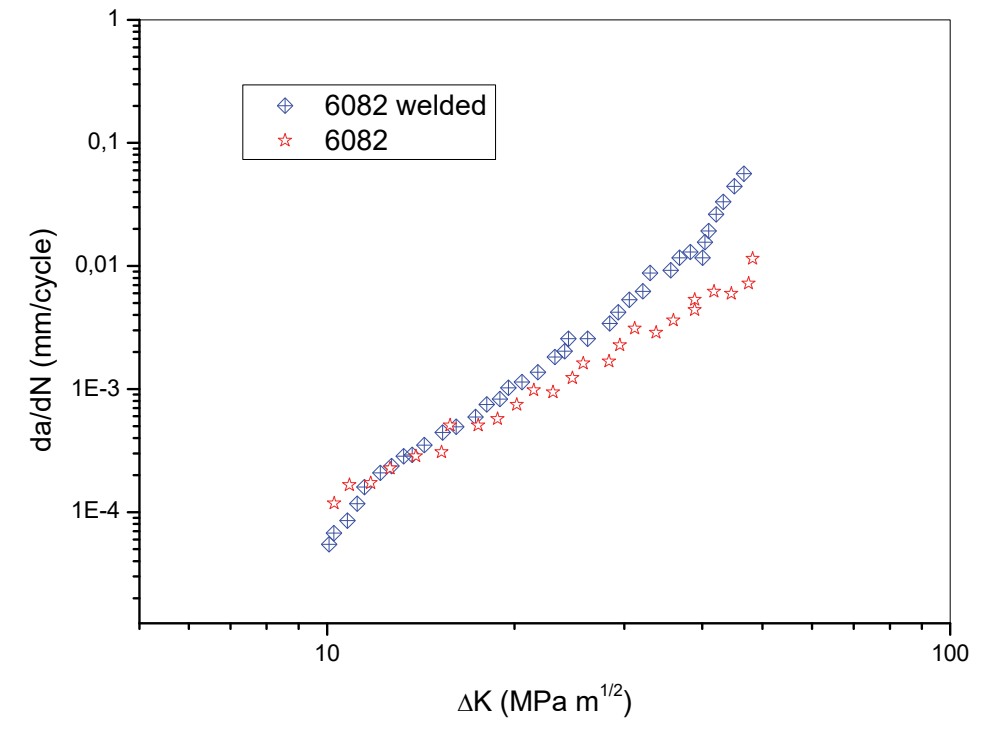

Figure 5: Evolution of the cracking speed as a function of $\Delta \mathrm{K}$ for the two materials.

In order to compare more clearly and more systematically the evolution of the cracking rate in the two grades, we chose to represent them by their respective linear regression lines obtained from the experimental points (seven point method) on the linear parts of the curves.

Indeed, we can notice that the curves present an almost rectilinear look on a large part of the domain explored, being able to be presented by PARIS' law of the form:

$$
\frac{d a}{d N}=C(\Delta K)^{m}
$$

The results of the cracking tests obtained in the two materials respectively recorded in the Tab. (3). 


\begin{tabular}{ccc}
\hline \multicolumn{1}{c}{ Alloy } & Paris' law & $\Delta \mathrm{K}$ \\
6082-T6 & $\mathrm{da} / \mathrm{dN}=7.41 \mathrm{E}^{-8} \Delta \mathrm{K}^{3.02}$ & 10 to $47 \mathrm{MPa} \sqrt{\mathrm{m}}$ \\
6082-T6 FSW & $\mathrm{da} / \mathrm{dN}=3.32 \mathrm{E}^{-14} \Delta \mathrm{K}^{7.32}$ & 10 to $45 \mathrm{MPa} \sqrt{\mathrm{m}}$ \\
\hline
\end{tabular}

Table 3: Equations characterizing the Paris' law in the different zones studied.

The cracking rate $\mathrm{da} / \mathrm{dN}$, for low values of $(\Delta \mathrm{K}<10)$ is decreasing respectively in both cases $(6082-\mathrm{T} 6$ and $6082-\mathrm{T} 6 \mathrm{FSW})$, however, this gap decreases as increases, which means that: microstructure in the two shades possesses almost the same appearance and the same characteristics. In this area (typical of Paris), the cracking rate is almost similar in the two materials.

\section{MATERIAL AND NUMERICAL STUDY ON AA5083-H111}

\section{Introduction}

7 he development of a numerical model allows us not only to simulate the FSW welding process, but also to make a parametric study and vary the welding conditions as desired. Song and Kovacevic have modeled the heat transfer in FSW using the finite difference method [4, 5]. Few papers have dealt directly with the modeling of thermomechanical stresses in FSW. Chao [6] proposed a model to predict the thermal history and the subsequent thermal stress and distortion of the workpiece without involving the the tool mechanical effect. Dong [7] developed several models to deal separately with the subproblems of heat transfer, material flow, and plastic flow. From the point of physics for the FSW process, the tool mechanical effect needs to be included into the thermo-mechanical model.

C.M. Chen, R. Kovacevic has considered the the tool mechanical effect (only the shoulder was included) [8].

The model used is based on the model developed by ANSYS, which took as a reference the the Zhu and Chao model. The approach presented in this article is more realistic, because it takes into consideration the whole tool: the shoulder and the pin, what it approaches us to reality.

The main parameters affecting the mechanical behaviour are multiple: the rotational and advancing speed, the tool size and the tool penetration. However, the parameters taken under consideration are the rotation speed, the welding speed and material change. We observed the residual stress and the heat distribution.

\section{Experimental Reference Study on A A 5083 H111}

To be able to compare and validate the numerical study we chose the experimental study on the material AA $5083 \mathrm{H} 111$. The results obtained by GHAZI [3], on another material AA 5083, by varying the welding parameters, rotational and welding speed, led to identify the optimal welding parameters. The alloy studied is Al 5083H111, which is an Al-Mg (Tab.4) in the H111 state (deformed by $25 \%$ by rolling). This strain hardening alloy will serve us to understand the different phenomena occurring during welding without involving precipitation. The alloy 5083H111 was chosen because it has magnesium and manganese levels fairly close to those of the alloy 2024 used in aeronautical structures for the fuselage. The chemical composition of Aluminum Al 5083H111 is given by the Tab. 4. The mechanical properties of the aluminum alloy were determined along the longitudinal directions L. The following table shows the material properties:

\begin{tabular}{|c|c|c|c|c|c|c|c|c|}
\hline $\mathrm{Al}$ & $\mathrm{Si}$ & $\mathrm{Fe}$ & $\mathrm{Cu}$ & $\mathrm{Mn}$ & $\mathrm{Mg}$ & $\mathrm{Cr}$ & $\mathrm{Zn}$ & $\mathrm{Ti}$ \\
\hline 0.15 & 0.40 & 0.40 & 0.10 & 0.10 & 4.90 & 0.25 & 0.25 & 0.15 \\
\hline \multicolumn{2}{|c|}{$\mathrm{E}[\mathrm{MPa}]$} & YS[MPa] & & UTS[MPa] & & $\mathrm{A}[\%]$ & $\mathrm{Hv}$ & $\mathrm{K}\left[/ \mathrm{cm}^{2}\right]$ \\
\hline \multicolumn{2}{|c|}{71008} & 155 & & 236 & & 16.5 & 88 & 45 \\
\hline
\end{tabular}

Table 4: Plates material characteristics: Aluminum Alloy 5083H111.

The welding parameters are shown in the Tab. 6. 


\begin{tabular}{cc}
\hline Density $\left(\mathrm{Kg} / \mathrm{m}^{3}\right)$ & 2660 \\
Thermal conductivity $(\mathrm{w} / \mathrm{m} . \mathrm{K})$ & $110-140$ \\
Thermal expansion coefficient $\mathrm{K}^{-1}$ & $24.210^{-6}$ \\
Specific heat $\left(\mathrm{J} / \mathrm{Kg}^{\circ} \mathrm{C}\right)$ & 900 \\
\hline
\end{tabular}

Table 5: Plates material other mechanical and thermal characteristics.

\begin{tabular}{ccccc}
\hline $\begin{array}{c}\text { Speed of rotation } \\
\omega[\mathrm{rpm}]\end{array}$ & 710 & 1000 & 1400 & 2000 \\
& 40 & 40 & 40 & 40 \\
& 80 & 80 & 80 & 80 \\
Welding speed & 100 & 100 & 100 & 100 \\
V [mm/min] & 200 & 200 & 200 & 200 \\
& 400 & 400 & 400 & 400 \\
\hline
\end{tabular}

Table 6: Welding parameter (speed of rotation - welding speed).

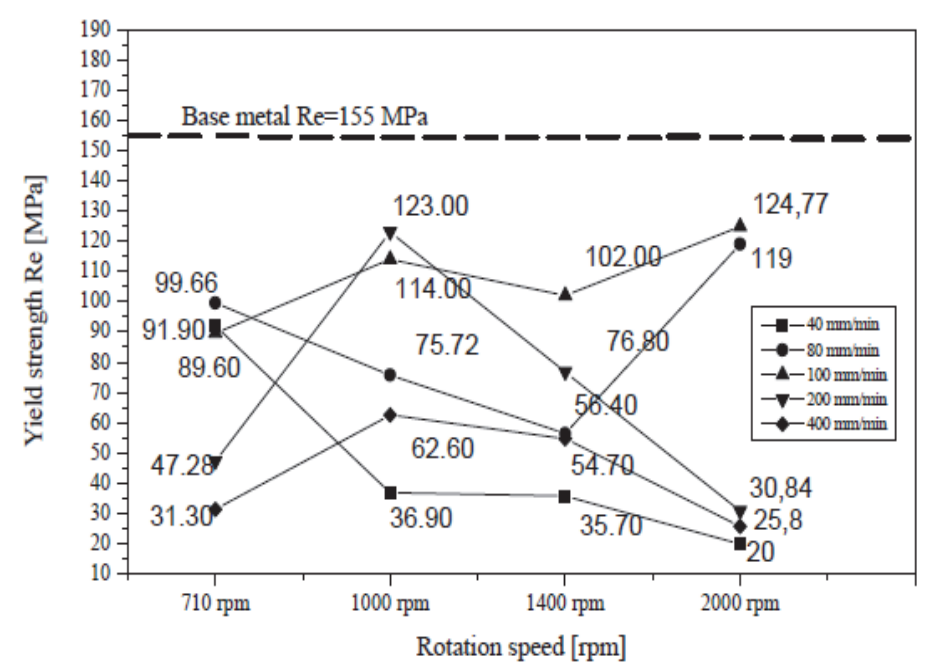

(a)

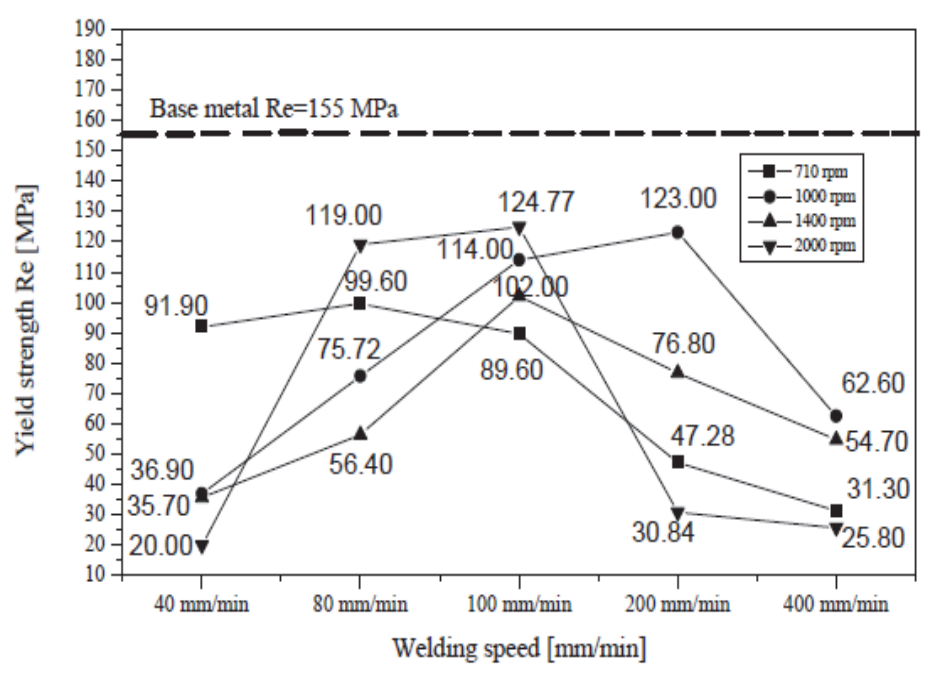

(b)

Figure 6: a) Variation of the elastic limit $R_{e}$ as a function of the rotational speed. b) Variation of the elastic limit $R_{e}$ as a function of the welding speed. 
The analysis of the tensile curves, clearly shows the variation of the elastic limit Re as a function of the variation of the rotational speed and the welding speed (Fig. 6).

Tensile tests have shown that these parameters give a good quality of welding:

- [710 $\mathrm{rpm}, 80 \mathrm{~mm} / \mathrm{min}]$.

- [1000 rpm, $100 \mathrm{~mm} / \mathrm{min}] ;[1000 \mathrm{rpm}, 200 \mathrm{~mm} / \mathrm{min}]$.

- [1400 rpm, $100 \mathrm{~mm} / \mathrm{min}]$.

- [2000 rpm, $80 \mathrm{~mm} / \mathrm{min}] ;[2000 \mathrm{rpm}, 100 \mathrm{~mm} / \mathrm{min}]$

\section{Modeling and Meshing}

For reducing the calculation time, dimensions are reduced. The reduced model is constituted by two rectangular shaped plates $1 \times 0.7 \times 0.1 \mathrm{~mm}$. The tool shoulder diameter is $0.2 \mathrm{~mm}$. the pin has a height of $0.3 \mathrm{~mm}$.

A direct coupled-field analysis is performed on a reduced-scale version of the Zhu and Chao model [6]. Also, rather than using a moving heat source as in the reference model, a rotating and moving tool is used for a more realistic simulation.

The simulation welds two Alu alloy 5083 H111 plates (workpiece) with a cylindrical shape tool, as shown in the Fig. 7. The FSW process was simulated taking into account a fully three-dimensional model, a thermo-mechanical analysis was developed with ANSYS software. Both the workpiece and the tool are modeled using coupled-field element SOLID226. The contact pairs has (contact analysis) was identified by the two elements CONTA174 and TARGE170 for contact and target surfaces (Fig. 8).

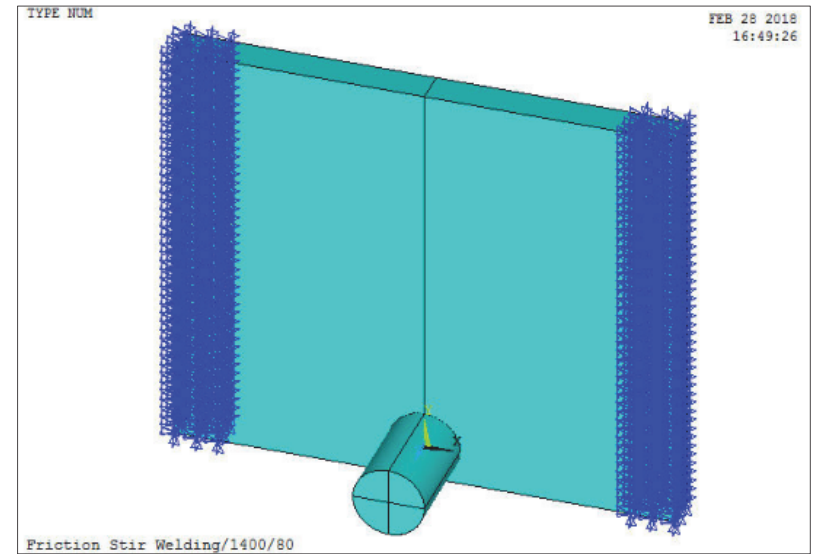

Figure 7: Geometry of the workpiece and tool by ANSYS.

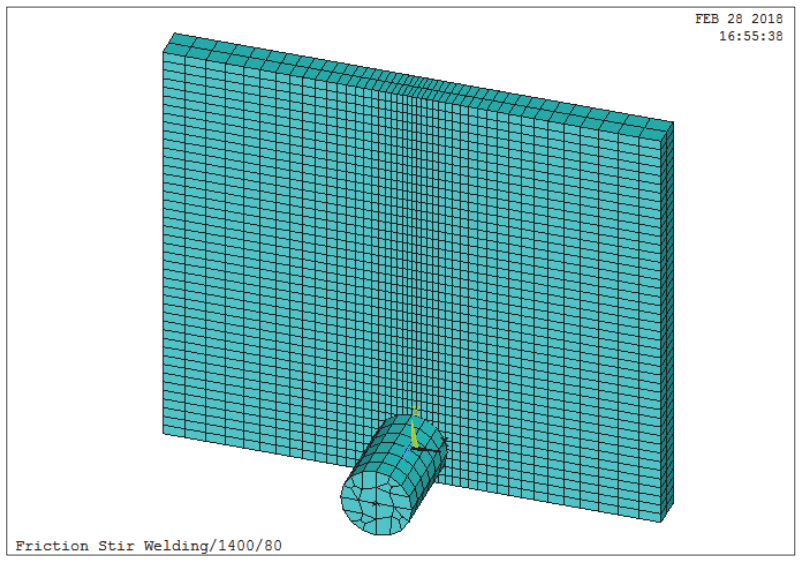

Figure 8: Finite Element mesh of FSW.

\section{Mechanical Boundary Conditions}

The workpiece is fixed by clamping each plate [1]. The clamped portions of the plates are constrained in all directions. To simulate support at the bottom of the plates, all bottom nodes of the workpiece are constrained in the perpendicular direction (z direction).

\section{Thermal Boundary Conditions}

The frictional and plastic heat generated during the FSW process propagates rapidly into remote regions of the plates. On the top and side surfaces of the workpiece, convection and radiation account for heat loss to the ambient. Conduction losses also occur from the bottom surface of the workpiece to the backing plate.

\section{Mechanical and physical properties}

Accurate temperature calculation is critical to the FSW process because the stresses and strains developed in the weld are temperature-dependent. Thermal properties of the Alluminium Alloy $5083 \mathrm{H} 111$ plates such as thermal conductivity, specific heat, and density are temperature-dependent. Mechanical properties of the plates such as Young's modulus and the coefficient of thermal expansion are considered to be constant due to the limitations of data available in the literature. It is assumed that the plastic deformation of the material uses the von Mises yield criterion, as well as the associated flow rule and the work-hardening rule [6). Therefore, a bilinear isotropic hardening model is selected [1]. 


\section{Heat generation}

The friction between the shoulder and workpiece results in the biggest component of heating. From the heating aspect, the relative size of pin and shoulder is important, and the other design features are not critical. The shoulder also provides confinement for the heated volume of material.

The tool plunges into the workpiece, then rotates to generate heat. The depth and rotating speeds are critical parameters for the weld temperatures. The tool travels from one end of the welding line to the other [9].

\section{Loading}

The FSW process consists of three primary phases:

- Plunge -- The tool plunges slowly into the workpiece

- Dwell -- Friction between the rotating tool and workpiece generates heat at the initial tool position until the workpiece temperature reaches the value required for the welding.

- Traverse (or Traveling) -- The rotating tool moves along the weld line.

During the traverse phase, the temperature at the weld line region rises, but the maximum temperature values do not surpass the melting temperature of the workpiece material. As the temperature drops, a solid continuous joint appears between the two plates.

\section{NUMERICAL RESULTS AND DISCUSSION}

7 he mechanical properties studied are the longitudinal residual stress and temperature distribution. The analysis takes different translation speeds (40, 80, 100 and $200 \mathrm{~mm} / \mathrm{min})$ and two rotational speed (710 rpm and $1400 \mathrm{rpm})$.

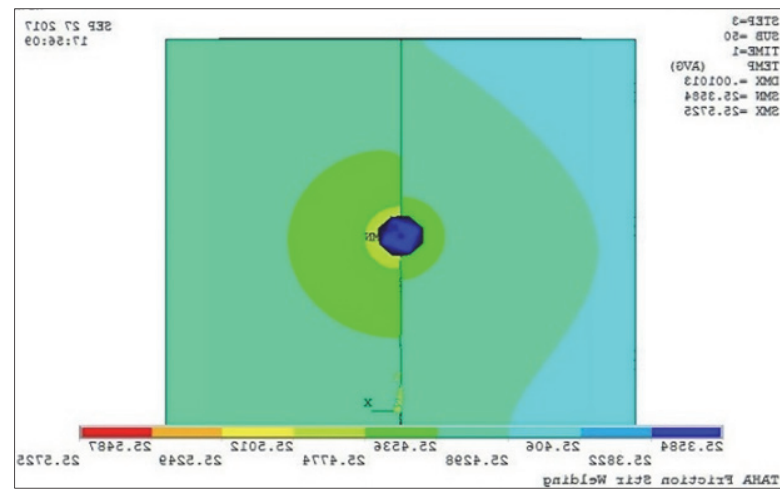

(a)

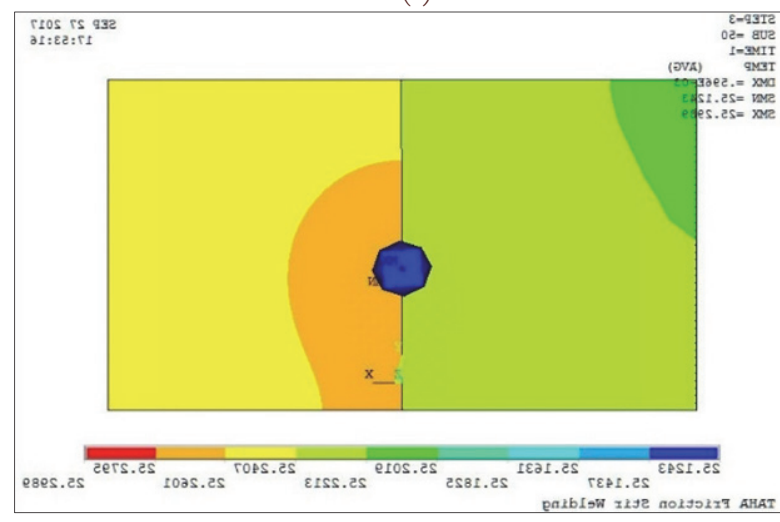

(c)

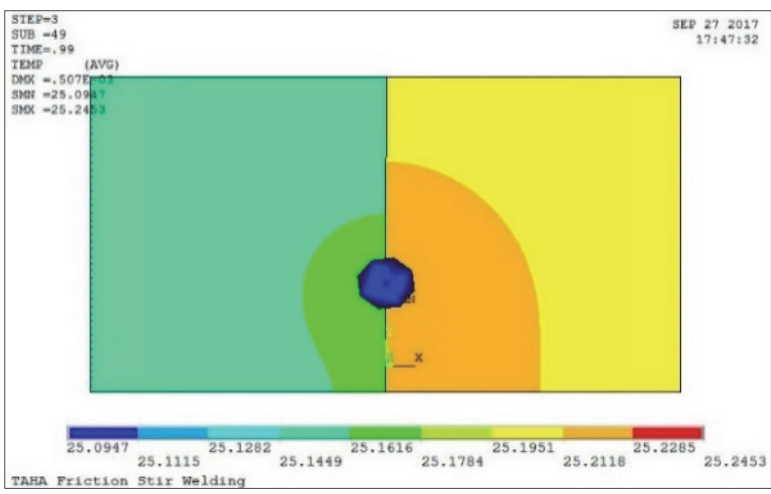

(b)

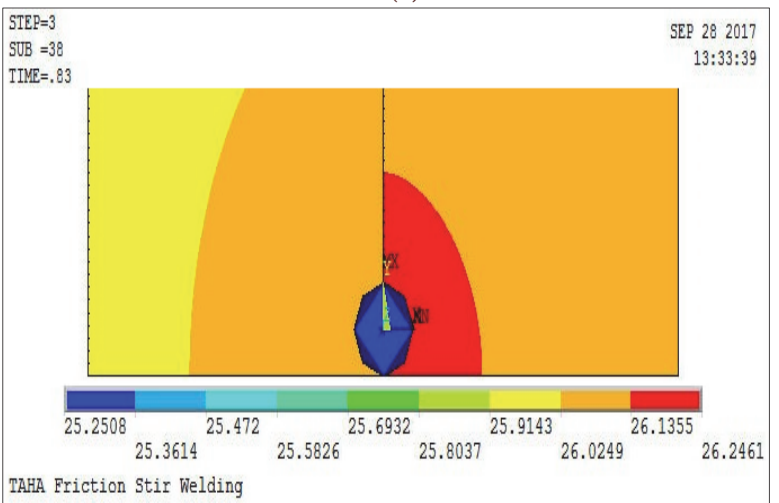

(d)

Figure 9: Heat distribution on cross-section of the workpiece: a) Welding speed of $40 \mathrm{~mm} / \mathrm{min}$, b) Welding speed of $80 \mathrm{~mm} / \mathrm{min}$, c) Welding speed of $100 \mathrm{~mm} / \mathrm{min}$, d) Welding speed of $200 \mathrm{~mm} / \mathrm{min}$. 


\section{Influence of Welding Speed on Heat generation}

From the Fig. 9, it is remarkable that decreasing the welding speed produces a hotter weld.

Heat generation during friction stir welding arises from two main sources: friction at the surface of the tool and the deformation of the material around the tool. Increasing the welding speed produces less work of deformation and in result, less heat generated.

The temperature distribution shows an asymmetric profile due to the stirring effect of the pin.

\section{Influence of welding Speed on Longitudinal Residual Stress}

It should be observed that residual stresses in FSW processes are due both to thermal and mechanical causes. The former are due to the friction forces work and to the deformation work both decaying into heat. The latter are strictly connected to the strong gradients of strain and strain rates occurring due to the tool pin action on the material to be welded and which determine relevant microstructure changes in the parent material but low influence in the residual stresses [10].

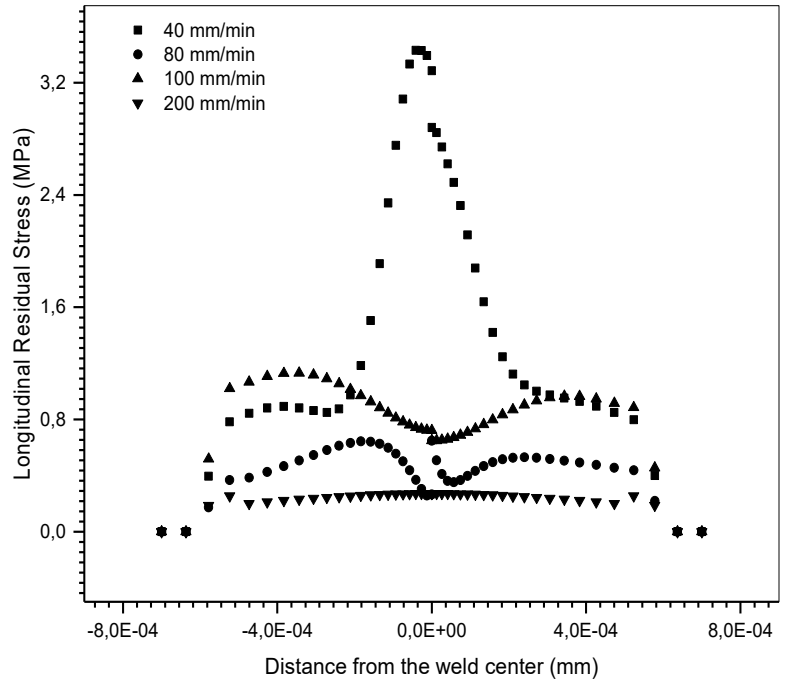

(a)

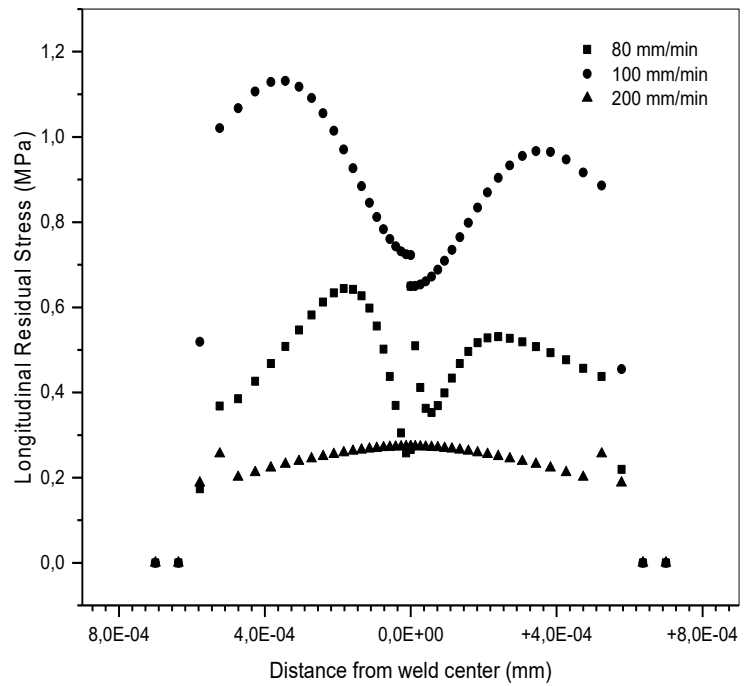

(b)

Figure 10: a) longitudinal stress profiles in a cross-section of the workpiece (Rotational speed: 710 rpm). b) Only 80 , 100 and $200 \mathrm{~mm} / \mathrm{min}$ welding speeds are represented.

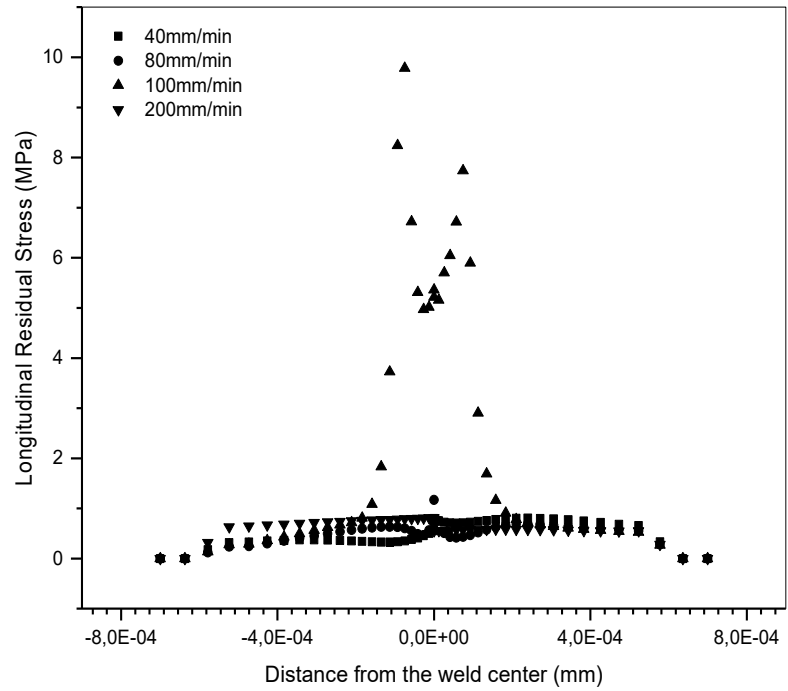

(a)

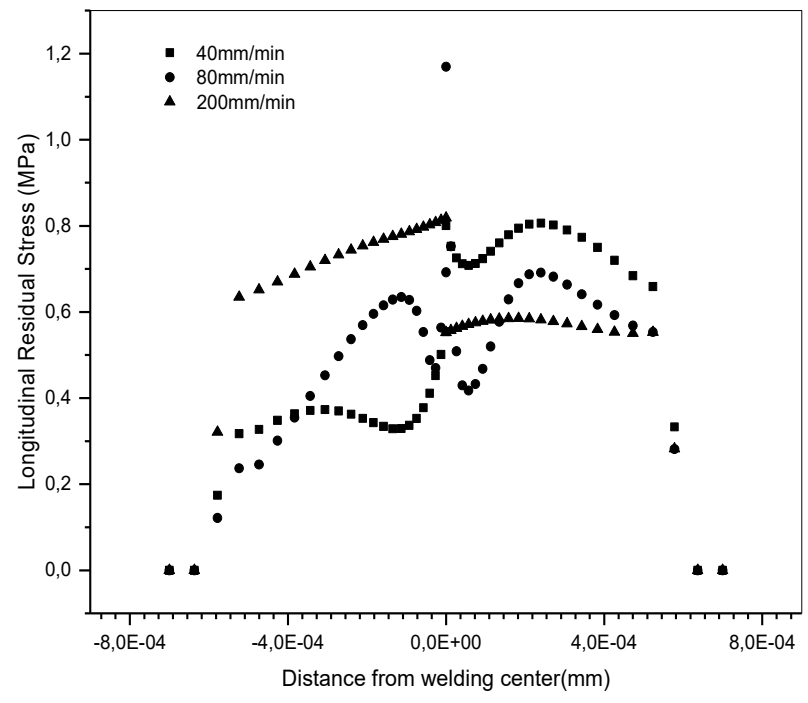

(b)

Figure 11: a) Longitudinal stress profiles in a cross-section of the work piece (Rotational speed: $1400 \mathrm{rpm})$. b) only 40,80 and $200 \mathrm{~mm} / \mathrm{min}$ welding speeds are represented. 
The graphs show the influence of the welding speed, on the longitudinal residual stresses LRS. We noticed that the following parameters are optimal:

(1400 rpm-100 mm/min), (1400 rpm-80 mm/min), (710 rpm-100 mm/min) (710 rpm -80 mm/min), which is consistent with the study of GHAZI already quoted [3].

The studies show that residual stress has three regions. There are the nugget region, the thermo-mechanically affected zone TMAZ and the heat affected zone HAZ. Each region has qualitatively or quantitively distinct values of microstructure, hardness and residual stress [11].

\section{Influence of rotational speed on heat generation}

Higher tool rotational speed resulted in a higher temperature and slower cooling rate in the friction stir processed FSP zone after welding.

Fig. 12 shows that the temperature is higher with the rotational speed $1400 \mathrm{rpm}$. In the retreating side, the temperature distribution is lower than the advancing side. The temperature is decreasing, when the distance from weld center is increasing.

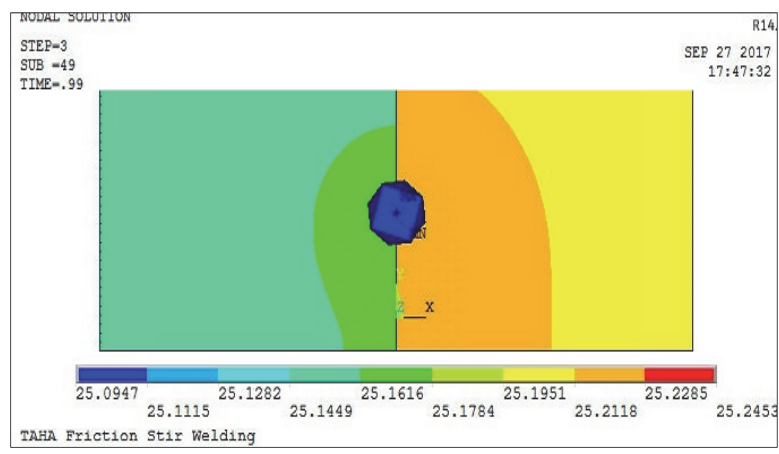

(a)

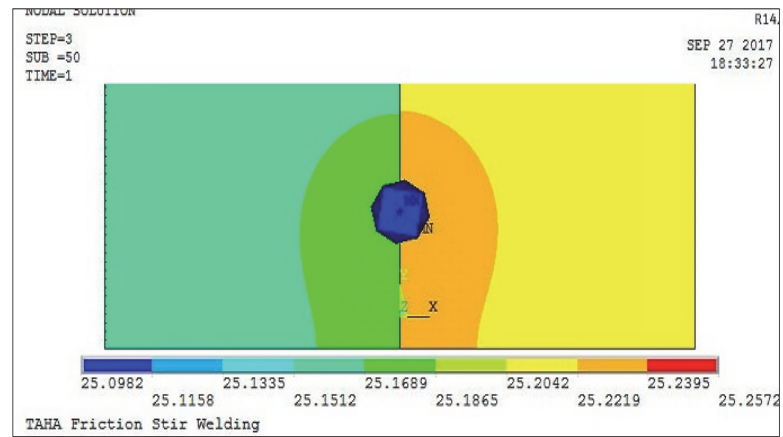

(b)

Figure 12: Heat distribution on cross-section of the workpiece : a) rotational speed of $1400 \mathrm{rpm}$, b) rotational speed of $710 \mathrm{rpm}$.

\section{Influence of Rotational Speed on Longitudinal Residual Stress}

Rotational speed appears to be the most significant process variable since it also tends to influence the translational velocity. Very high rotational speeds $(>10,000 \mathrm{rpm})$ could raise strain rate, and there by influence the recrystallisation process; which in turn could influence the FSW process [12].

At a constant welding speed of $80 \mathrm{~mm} / \mathrm{min}$, residual stresses increased as rotational speed augmented from 710 to 1400 $\mathrm{rpm}$. A higher rotational speed causes excessive release of stirred materials to the upper surface, which resultantly left voids in the FSP zone. Lower heat input condition due to lower rotational speed resulted in lack of stirring [13].

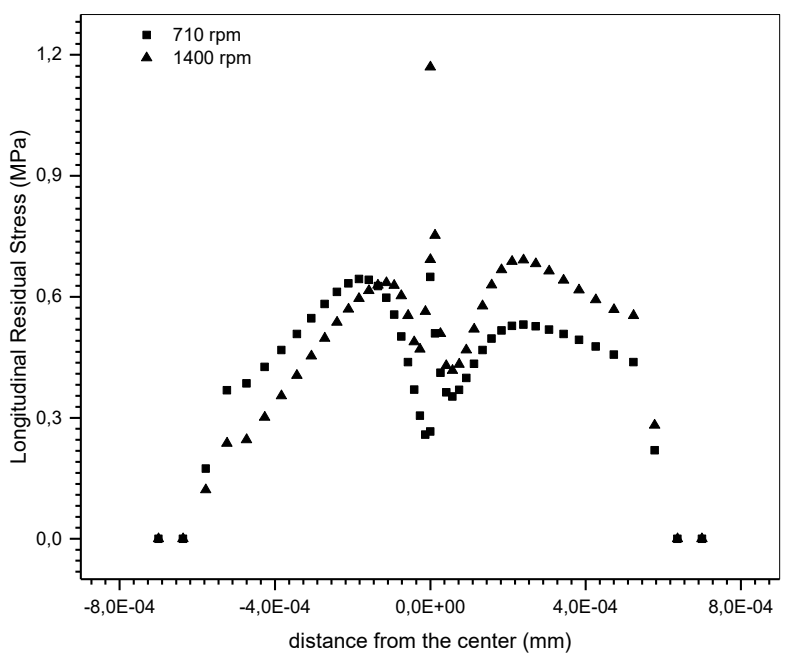

Figure 13: Influence of rotational speed on longitudinal residual stress.

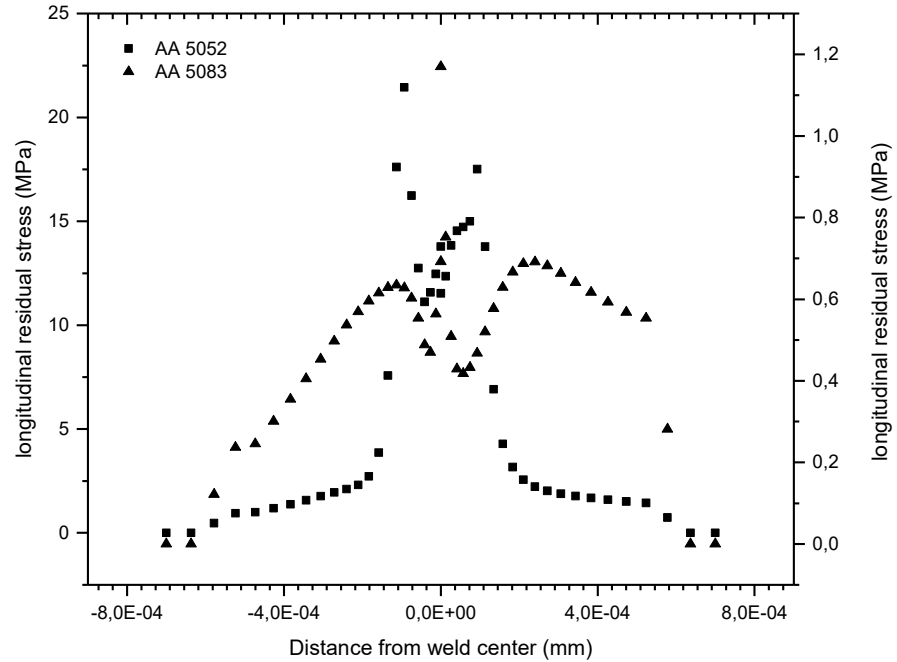

Figure 14: Influence of material properties on residual longitudinal stress. 
The heat input (generated by the friction between tool shoulder and base metal) increases with increase in tool rotational speed and decrease in welding speed. Low heat input causes the intermittent metal flow and improper stirring action around the tool pin due to insufficient plasticization of the base metal under the tool shoulder. On the other side, high heat input causes turbulent metal flow around the tool pin due to excess plasticization of base metal under the tool shoulder. Both these welding conditions produced defective welds. The base metal with low yield strength, low hardness and higher ductility can be plastically deformed very easily and the flow of plasticized metal around the non-consumable tool will also be uniform compared to the base metal with high strength, high hardness and low ductility. [14]

\section{Influence of Material Properties in the Longitudinal Residual Stress}

Fig. 14 shows that the material AA 5052 has undergone higher stresses at the nugget, TMAZ and less at TAZ, compared to AA 5083 alloy, which means higher deformation.

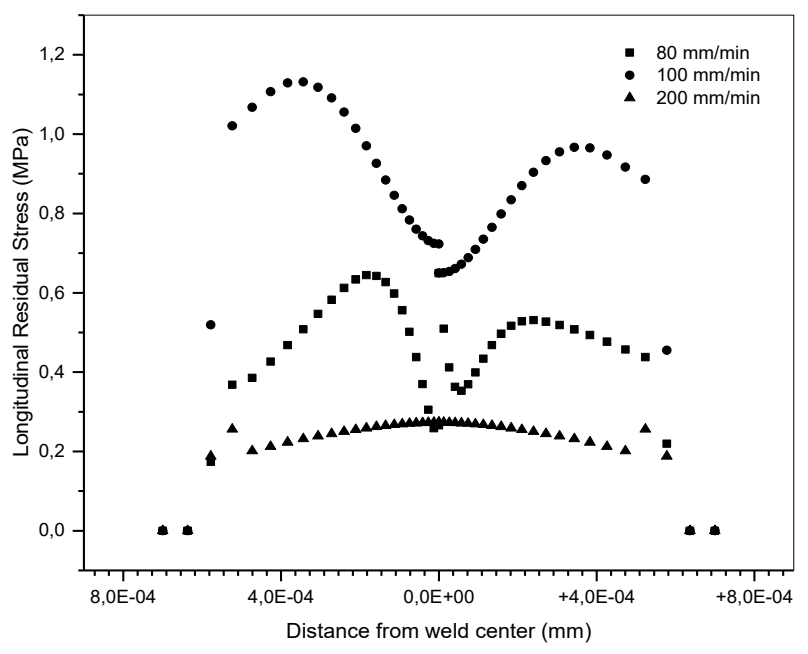

(a)

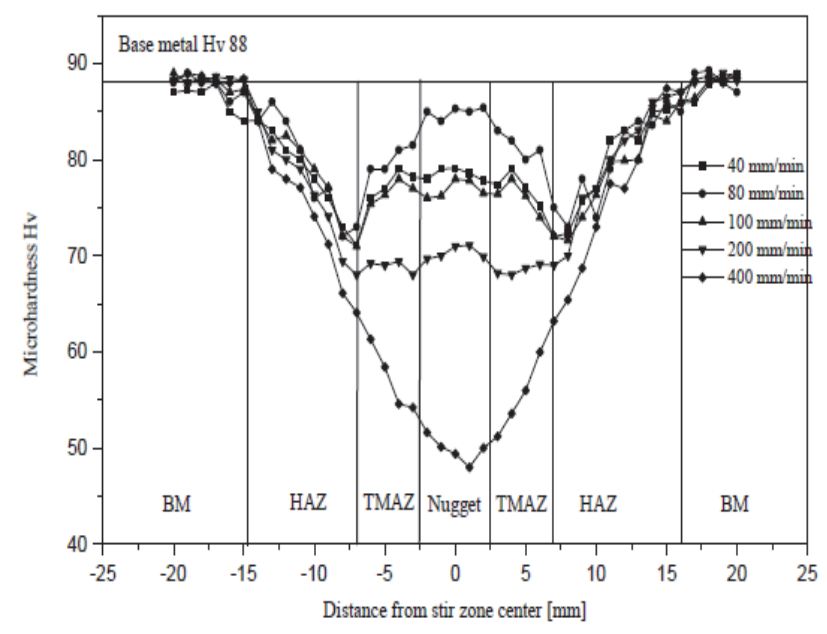

(b)

Figure 15: Comparison between: a) Influence of welding speed on LRS (710 rpm), b) Influence of welding speed on Micro-hardness [3].

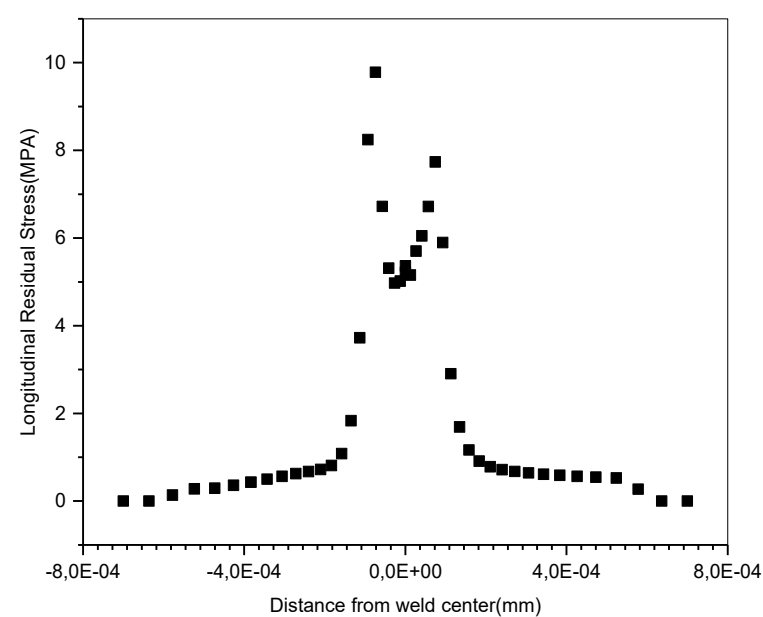

(a)

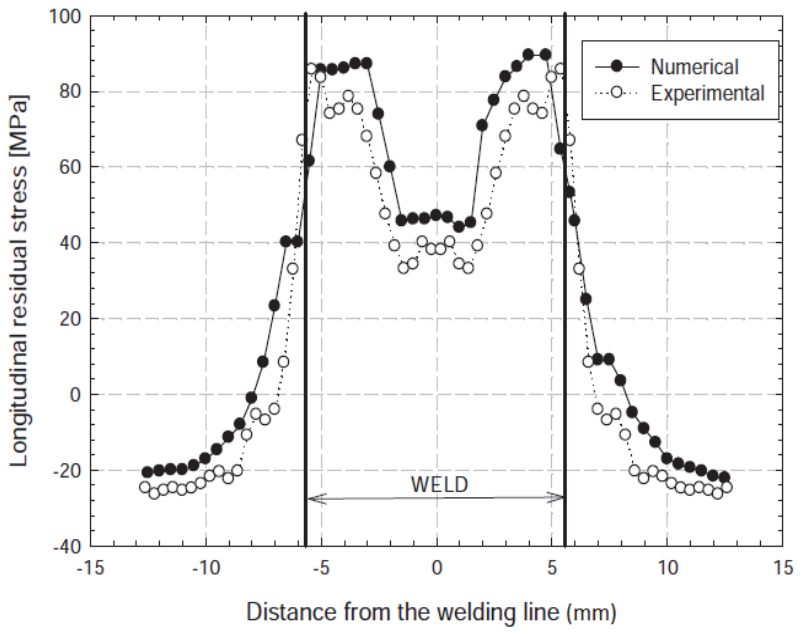

(b)

Figure 16: a) Longitudinal Residual stress with (1400 rpm, $100 \mathrm{~mm} / \mathrm{min})$, b) Experimental and numerical longitudinal stress profiles in a cross-section of the weld piece [10].

\section{Validation of Numerical Results}

Comparison With The Validation Study: Stress - Microhardness Relationship

The relationship between stress and strain (deformation) and microhardness is a factor to check the numerical model. Strain or reduced deformation is a term that expresses the trend of the deformation change among the material field. Strain is the 
deformation per unit length [15]. Applying a stress to material results in a strain. On the other side, hardness is a measure of the resistance to localized plastic deformation induced by either mechanical indentation or abrasion.

From these definitions, it is deductible that the relationship between hardness and strain is an inverse relationship, to the opposite of the positive relationship between stress and strain. From this perspective, the longitudinal stress results in the numerical study shown in the Figs. $(10,11,12,13)$, are comparable to the micro-hardness results, obtained by GHAZI [3]. The inverse relationship is shown in Fig. 16.

By Longitudinal stress Profile in a cross-section of the weld piece:

Fig. (16-a) shows longitudinal stress profile, achieved with ANSYS APDL for a rotation speed equal to $1400 \mathrm{rpm}$, and a welding speed equal to $100 \mathrm{~mm} / \mathrm{min}$.

Fig. (16-b) shows the residual stress profiles used as a typical stress profile for comparaison. It can be seen that the residual stresses are compressive in the weld with external regions subjected to compressive stresses [10]. The comparison between Figs. (16-a) and (16-b), shows a similarity.

\section{CONCLUSIONS}

\section{Experimental}

- The conventional yield stress in the base material AA 6082-T6 (314 MPa) is well above the yield strength in FSW welded specimens AA 6082 - T6 FSW (260 MPa).

- The cracking rate $\mathrm{da} / \mathrm{dN}$, for low values of $(\Delta \mathrm{K}<10)$ is almost similar in the two materials.

Numerical

- Decreasing the welding speed produces a hotter weld.

- The optimal parameters are these combinations (1400 rpm-100 mm/min), (1400 rpm - $80 \mathrm{~mm} / \mathrm{min}),(710 \mathrm{rpm}-100$ $\mathrm{mm} / \mathrm{min}$ ) and $(710 \mathrm{rpm}-80 \mathrm{~mm} / \mathrm{min})$.

- Higher temperature is generated with the rotational speed $1400 \mathrm{rpm}$, then with $710 \mathrm{rpm}$, for a constant welding speed 80 $\mathrm{mm} / \mathrm{min}$.

- Residual stress increased as rotational speed augmented from 710 to $1400 \mathrm{rpm}$.

- Comparing AA 5083 with AA 5052, the latter has undergone higher stresses. This is translated into deformation, which means less weldabilty.

Validation

- The longitudinal stress results in the numerical study shown in Figs. (10, 11, 12 and 13) are comparable to the microhardness results obtained by GHAZI [3]. The inverse relationship is shown in the Fig. 17.

- The longitudinal residual stresses LRS profile resulted in the numerical study, shows similarity with the typical LRS profile [10].

\section{REFERENCES}

[1] ANSYS 14.5 Help// Technology Demonstration Guide // 30. Friction Stir Welding (FSW) Simulation.

[2] He, X., Gu, F. and Ball, A. (2014). A Review Of Numerical Analysis Of Friction Stir Welding, Progress In Materials Science 65, pp. 1-66.

[3] Ghazi, A. (2013). Caractérisation Mécanique des Assemblages Soudés par Friction Malaxage (Etude Numérique et Expérimentale).

[4] Song, M. and Kovacevic, R. (2002). Numerical Simulation And Experimental Analysis Of Heat Transfer Process In Friction Stir Welding Process, Proceeding Of Institution Of Mechanical Engineers, Part B, Journal Of Engineering Manufacture 216 (12), pp. 73-85.

[5] Song, M. and Kovacevic, R. (2003). Thermal Modeling Of Friction Stir Welding In A Moving Coordinate And Its Validation, International Journal Of Machine Tool And Manufacturing 43 (6), pp. 605-615.

[6] Zhu, X. K. and Chao, Y. J. (2004). Numerical Simulation of Transient Temperature and Residual Stresses in Friction Stir Welding of 304L Stainless Steel. Journal of Materials Processing Technology 146(2), pp. 263-272.

[7] Dong, P., Lu, F., Hong, J.K. and Cao, Z. (2001). Coupled Thermomechanical Analysis Of Friction Stir Welding Process Using Simplified Models, Science And Technology Of Welding And Joining 6(5), pp. 281-287. 
[8] Chen, C.M. and Kovacevic, R. (2003). Finite Element Modeling Of Friction Stir Welding-Thermal And Thermomechanical Analysis. Science Direct, International Journal Of Machine Tools \& Manufacture 43, pp. 1319_ 1326.

[9] Mishra, R.S. and Ma, Z.Y. (2005). Friction stir welding and processing, Materials Science and Engineering R, 50(1-2), pp. 1-78.

[10] Buffa, G., Fratini, L. and Pasta, S. (2009). Residual Stresses In Friction Stir Welding: Numerical Simulation And Experimental Verification, JCPDS-International Centre for Diffraction Data, pp. 444-453

[11] Kambouz, Y., Benguediab, M. and Bouchouicha, B. (2017). Numerical Study of the Mechanical Behavior and Fatigue in a Weld Bead by Friction Stir for a 6082-T6 Aluminum Alloy. Mechanics and Mechanical Engineering, 21(1), pp. 6783.

[12] Elangovan, K. and Balasubramanian, V. (2007). Influences of pin profile and rotational speed of the tool on the formation of friction stir processing zone in AA2219 aluminium alloy, Material Science and Engineering: A, 459 (1-2), pp. 7-18.

[13] Elangovan, K., Balasubramanian, V. and Valliapan, M. (2008). Effect of Tool Pin Profile and Tool Rotational Speed on Mechanical Properties of Friction Stir Welded AA6061 Aluminium Alloy Materials and Manufacturing Processes, 23(3), pp. 251-260.

[14] Fernandez, G.J., and Murr, L.E. (2004). Characterization of tool wear and weld optimization in the friction-stir welding of cast aluminum 359+20\% SiC metal-matrix composite. Materials Characteization 52(1), pp. 65-75.

[15] Beer, F. P., Russell Johnston Jr., E., DeWolf, J. T. and Mazurek, D.F. (2009). Mechanics of materials (5th ed). Mc Graw Hill, p.49. 